\title{
A RETÓRICA NEOLIBERAL VERSUS FORMAÇÃO HUMANÍSTICA EM TEXTOS DE LIVROS DIDÁTICOS DE LI
}

\author{
Maria Elizete Pereira dos ANJOS \\ Universidade Estadual de Goiás
}

RESUMO: O presente artigo visa discutir as orientações utilitaristas da educação, pautadas na retórica neoliberal em contraponto com o modelo de educação humanista e omnilateral (Gramski, 1985), implícitas em textos de manuais de ensino de língua inglesa. Para tanto, foram analisados dois textos: o primeiro, extraído do livro Inglês para o Ensino Médio de Sara Rubim e Mariza Ferrari e o segundo do It's English-Ensino Médio da FISK. Os textos compõem a primeira unidade de ambos os livros. A intenção é discutir como os referidos manuais se diferem quando exortam o aluno para a importância do aprendizado de inglês, sendo que o primeiro utiliza um discurso que tende a colocar a escola no âmbito do mercado e das técnicas de gerenciamento, esvaziando, assim, o conteúdo político da cidadania, revelando a presença de orientações utilitaristas da educação que prepara o indivíduo apenas para o mercado do trabalho. $\mathrm{O}$ segundo relaciona o aprendizado de inglês com elementos da cultura do aluno enquanto propõe reflexões e indagações acerca da real importância da língua inglesa na vida do aprendiz, levando o mesmo à reflexão e à consciência crítica do papel e do lugar que uma língua estrangeira ocupa na vida das pessoas na atualidade, revelando uma intenção de projeto de educação pautada no modelo humanista, na omnilateralidade.

PALAVRAS-CHAVE: Neoliberalismo; Educação Humanista; Livro Didático de Língua Inglesa.

ABSTRACT: This article aims to discuss the utilitarian orientations of education, based on neoliberal rhetoric in counterpoint with the humanistic and omnilateral education model (Gramski, 1985), implicit in texts of English language teaching manuals. For that, two texts were analyzed: the first, extracted from the English textbook for Sara Rubim and Mariza Ferrari Secondary School and the second from It's English - FISK High School. The texts make up the first unit of both books. The intention is to discuss how these manuals differ when they exhort the student to the importance of learning English, and the first uses a discourse that tends to place the school within the market and management techniques, thus depleting the Political content of citizenship, revealing the presence of utilitarian orientations of education that prepares the individual only for the labor market. The second relates the learning of English with elements of the student's culture while proposing reflections and inquiries about the real importance of the English language in the life of the learner, leading to the reflection and the critical awareness of the role and place that a foreign language occupies in the Life of people today, revealing an intention of education project based on the humanist model, on the omnilaterality.

KEY-WORDS: Neoliberalism; Humanist Education; English Language Textbook.

\section{Introdução}

O livro didático de língua estrangeira, além de se configurar em um instrumento de ensino- aprendizagem é também um forte agente cultural que colabora para formação dos sujeitos que com ele se relaciona, intervindo na sua maneira de compreender, sentir e relacionar com o mundo que o cerca. Com base nesse pressuposto, a questão da produção de livros didáticos para o ensino de língua estrangeira sempre esteve relacionada às tradições, questões culturais e, sobretudo, às ideologias que geralmente revelam o projeto de educação, de cultura e de sociedade à que se filiam os sujeitos que o produzem e deles fazem uso. 
Nesse sentido, nossa opção por analisar textos de livros didáticos de língua inglesa consiste no fato de entender que esses materiais transportam aspectos políticos, culturais e ideológicos em relação aos conteúdos que apresentam e, sobretudo, à forma como abordam os estudantes para o aprendizado desses conteúdos. Assim, optamos por analisar dois textos de dois livros de língua inglesa, (doravante LI) para o ensino médio, escritos com um objetivo comum: persuadir o aluno desse nível de ensino da importância do aprendizado de uma língua estrangeira (doravante LE) na atualidade.

Para empreender os objetivos aqui propostos, quais sejam, discutir as orientações utilitaristas da educação, pautadas na retórica neoliberal em contraponto com o modelo de educação humanista e omnilateral implícitas em textos de manuais de ensino de língua inglesa, este texto foi divido em três partes. A primeira discute as características do modelo Neoliberal de educação em contraponto com o modelo Humanista, evidenciando as implicações desses modelos na formação do indivíduo na sociedade capitalista. A segunda trata do papel que o livro didático ( doravante LD) ocupa nos contextos formais de ensino de LI, sendo que em alguns deles se constitui no fio condutor da aula, levando tanto o professor quanto os estudantes a estabelecerem links com outros recursos didáticos. A terceira e última parte traz uma análise de dois textos extraídos de dois livros didáticos de LI para o ensino médio, que retrata o modelo de educação ( humanista ou neoliberal) que esses textos revelam na forma como exortam o aluno do ensino médio a aprender inglês.

A intenção não é de estabelecer relação hieráquica entre as abordagens adotadas pelos manuais de ensino analisados, mas de colaborar para formação de consciência crítica dos sujeitos que deles fazem uso no que tange à compreensão do "modelo de educação, de sociedade e de cultura a que se filiam” (BRZEZINSKI, 2014) seus autores e usuários.

Aponta-se, nesse sentido, para a importância de profissionais de área de LE assumirem uma postura política no momento da escolha do LD, que revele que suas práticas discursivas estão associadas a visões particulares do mundo (crenças e valores) de grupos sociais e culturais particulares e que, portanto, a opção por um ou outro LD irá revelar um processo de construção identitária no qual professores e alunos podem, também, se reconfigurar.

\section{O modelo neoliberal de educação em contraponto com a formação humanística}

A escola e principalmente a sala de aula se constituem em espaços em que se materializam as acepções sobre a política e a idealização que as sociedades instituem para si próprias, como projeto educativo, de sociedade e de cultura à que se filiam e tentam edificar.

Nesse sentido o projeto de educação que uma determinada instituição educativa elege pode intencionar a formação do indivíduo para o mercado de trabalho somente ou para formação para a cidadania. A primeira perspectiva está relacionada ao modelo neoliberal educacional, em que a educação consiste no principal capital humano, pois potencializa o fator trabalho, consiste num investimento comercial como qualquer outro. (FRIGOTTO, 1986, apud BIANCHETTI, 2011).

O neoliberalismo, de forma simplória, pode ser concebido como um conjunto de ideias políticas e econômicas capitalistas que defende a não participação do estado na economia.

De acordo com Galvão (1997), o centro de toda ideia neoliberal é o mercado e, com isso, o consumo. Foi instituído na chamada Escola de Chicago, através dos postulados de dois economicistas, Milton Friedmann e Frederic Hayek, na crise econômica dos anos 60, sob acusação de ser o Estado o responsável pela crise.

O projeto neoliberal vê a educação como:

mercadoria e nega a formação para o trabalho que é firmada em bases humanistas e praxiológicas indispensáveis à construção, na teia das relações 
sociais, de um professor capaz de ser mediador entre o conhecimento, a tecnologia , os saberes e o ser que aprende. ( BRZEZINSKI, 2014,p.116).

Em outras palavras, no neoliberalismo a escola é concebida no âmbito do mercado e das técnicas de gerenciamento. Os direitos do consumidor substituem o conteúdo político da cidadania. É como consumidores que o neoliberalismo vê alunos e seus pais.

No discurso neoliberal a educação se divorcia do campo social e político, introduz no mercado e passa a funcionar a sua semelhança. Assim, vale retomar Albert Hirschman (1992), quando argumenta que esse discurso apoia-se na "tese da ameaça", ou seja, num artifício retórico da reação, que ressalta o risco de estagnação que o Estado do Bem-Estar Social concebe para a livre iniciativa: para a produção de bens de consumo, maquinário, para o mercado, para a nova ordem mundial e, sobretudo para a qualidade total.

De acordo com as orientações de Brzezinski (2014), a qualidade total rejeita o conhecimento como base fundamental da formação docente e apregoa que as questões relacionadas à educação e à formação humanística estejam condicionadas ao capital.

Essa postura, por sua vez, irá colaborar para formação do homem unilateral, dividido pela força do trabalho, alienado pelo outro e pela própria natureza. No entanto o indivíduo não pode desenvolver-se omnilateralmente se não houver uma totalidade de forças produtivas e se não lhe for oportunizado o gozo dos bens espirituais, além dos materiais, e dos quais o trabalhador tem sido excluído em consequência da divisão do trabalho.

Ainda sobre o modelo que se contrapõe à formação omnilateral, Bianchetti (1996) apresenta uma das vertentes teóricas que sustentam a concepção neoliberal para a educação, conhecida como teoria do capital humano:

Essa teoria incorpora em seus fundamentos a lógica do mercado e a função da escola se reduz à formação de "recursos humanos" para a estrutura de produção. Nessa lógica, a articulação do sistema educativo com o sistema produtivo deve ser necessária. O primeiro deve responder de maneira direta à demanda do segundo. Deste modo o neoliberalismo, ao rejeitar a planificação social, deixa livre às leis da oferta e da demanda as características e orientação do sistema educativo. (BIANCHETTI, 1996, p.94)

As palavras de ordem da retórica neoliberal são qualidade total, modernização do ensino e da escola, ajustamento do ensino à concorrência do mercado internacional, anexação das tecnologias e linguagens da informática e da comunicação, deserção do Estado, financiamentos empresariais para as universidades, descentralização, pesquisas de ordem práticas e, sobretudo utilitárias, produtividade.

De acordo com autores como Bianchetti ( 2001), na concepção neoliberal:

Os indivíduos constituem as moléculas sociais do sistema econômico. O homem tomado como um todo possui as capacidades naturais que lhe permitem desenvolver-se contando com certas doses de instintos, somadas á sua racionalidade, vontade e desejos. (BIANCHETTI, 2001 p.71).

A junção dessas características auxiliará no desenvolvimento da consciência individual e da cultura coletiva, o que desencadeará o indivíduo num ser político. Já as Instituições sociais, no modelo neoliberal, são criação do homem para relacionar os interesses individuais na forma de um somatório, e o estado é concebido como "uma pessoa, com a capacidade de acumular poderes ilimitados" ( BIANCHETTI, 2001 p.77).

$\mathrm{Na}$ perspectiva neoliberal, a educação restringe-se à função de produzir e de reproduzir a força de trabalho para o capital, de formar indivíduos ideologicamente de 
acordo com os interesses do capital e de servir como segmento do mercado a ser explorado pelo setor privado.

(...) A relação do neoliberalismo com a educação se dá em diversos aspectos, tais como: as concepções pedagógicas, a avaliação escolar; a municipalização da educação, a exclusão violenta dentro das escolas; a ideologia dos conteúdos: qualidade, quantidade e distribuição, privatização da educação" (CAPRIOGLIO et al, 2000, p.26).

Para a educação, o discurso neoliberal propõe uma espécie de tecnicismo reformado. As questões de cunho social, político, econômico e cultural da educação se transformam em problemas de caráter administrativos e técnicos. Nesse sentido, a escola ideal deve ser aquela que tem gestão eficiente para competir no mercado. $\mathrm{O}$ aluno é transformado em consumidor do ensino, e o professor, por sua vez, em funcionário habilitado e competente para preparar "seus clientes" para o mercado de trabalho e para realizar pesquisas práticas e utilitárias em curto prazo.

Identificar, analisar e compreender a tendência neoliberal presente nesses aspectos, significa, sobretudo, compreender o projeto de educação, de sociedade e de cultura a que as instituições se filiam (BRNZENSKI, 2014) e, com isso, construir bases sólidas que permitam um olhar crítico para as ações que decorrem desses modelos.

O projeto de educação neoliberal quer atrelar "a educação escolar à preparação para o trabalho e a pesquisa acadêmica ao imperativo do mercado ou às necessidades da livre iniciativa"(MARRACH, 1996, p. 46-48), contrapõem com o modelo humanista, de formação integral que visa preparar o indivíduo para o mundo do trabalho, para a cidadania. Essa educação é emancipadora, não é alienada e contribui para erradicação das desigualdades econômicas e sociais.

No modelo de educação humanística a ideologia é que a escola seja lugar de formação de seres humanos. Nessa perspectiva, a escola deve fazer com que os alunos integrem o corpo social onde vivem e também prepare para o mundo do trabalho, não apenas na expectativa de formar pessoas para serem úteis, mas que seja um lugar para pensar a crítica a partir do conhecimento. Que forme um aluno autônomo, que seja capaz de lançar um olhar crítico sobre o outro e, na mesma medida, responsável, que seja capaz de utilizar esse olhar na relação com o outro. Que seja um lugar essencialmente de emancipação humana ( ADORNO, 1995).

Nesse contexto, é válido citar o modelo de escola defendido por Gramsci (1985), cujo objetivo é que promova-se acesso a valores fundamentais de caráter humanista, favorecendo a conquista do que o estudioso denomina de auto-disciplina intelectual e autonomia moral que possibilitem posterior especialização, seja em que aspecto for: científico ou prático-produtivo. Acerca da experiência da escolarização, particularmente a inicial, Gramsci (1985) assevera que

A crise terá uma solução que, racionalmente, deveria seguir esta linha: escola única inicial de cultura geral, humanista, formativa, que equilibre equanimemente o desenvolvimento da capacidade de trabalhar manualmente (tecnicamente, industrialmente) e o desenvolvimento das capacidades de trabalho intelectual. Deste tipo de escola única, através de repetidas experiências de orientação profissional, passar-se-á a uma das escolas especializadas ou ao trabalho produtivo. (GRAMSCI, 1985 p. 118)

Nessa mesma perspectiva, observa-se que a intenção é que a escola contribua para formação do homem omnilateral, por meio do "desenvolvimento total, completo, multilateral em todos os sentidos e faculdades e das forças produtivas, das necessidades e da capacidade da sua satisfação"(MANACORDA, 1981, p. 78-79) 
Esse pensamento conflita com o modelo neoliberal em que a escola se torna um lugar de capital, de lucro, de manipulação do ser humano a serviço de poucos, não há lugar de desenvolvimento das relações humanas, pois é negada a relação com outro e, com isso, "renunciada a própria realidade humana" (MANACORDA, 1991, p.81).

Para Oliveira (1982) não se trata de prover educação apenas para transformar a população em força do trabalho, pois são necessidades que são definidas a priori como relevantes em si mesmas. Que elas terminem servindo, direta ou indiretamente, para o aumento da produtividade, não dissolve o fato principal, que é o de que, agora aquele aumento da produtividade que pode ser seu resultado não é mais seu pressuposto.

\section{Que modelos de educação podem revelar os textos dos livros didáticos de LI ?}

O que nos motivou a realizar essa análise foi a convicção de que o LD se constitui em um dos instrumentos mais importantes no ensino de língua estrangeira. Isso decorre, sobretudo, da falta de outros recursos na escola, considerados adequados para se ensinar língua estrangeira. Ademais, em alguns contextos de ensino o livro didático se constitui no fio condutor da aula, levando tanto o professor quanto os estudantes a estabelecerem links com outros materiais didáticos que possam ampliar, aprimorar, ilustrar, esclarecer conteúdos e conceitos apresentados inicialmente no livro.

Todavia, apesar de se constituir em um recurso fundamental no ensino de LI, nenhum livro didático é completo em si, pois sua eficácia está diretamente atrelada às metodologias, à proposta pedagógica da escola, entre outros aspectos, conforme assevera Almeida Filho (2013):

O horizonte que mantenho para materiais de ensino de línguas é o de materiais-fonte incompletos como se fossem planos incompletos aguardando uma finalidade de professores e suas turmas nos contextos reais em que estiverem imersos (ALMEIDA FILHO, 2013 p.15).

Isso nos permite dizer que a relevância do livro didático está relacionada ao fato de que ele pode ser um suporte para aprendizagem quando utilizado de "forma coordenada" (PEREIRA, 2013) com os objetivos traçados pelo docente para sua sala de aula. Com isso, os conteúdos, valores e comportamentos e atividades que o LD sugere devem estar relacionados com o que pensam os alunos e o com o que é ensinado pelo professor para fazer com que a classe avance na aprendizagem.

Para Kullman (2013), o livro didático além de servir como instrumento de ensino e aprendizagem é também um forte agente cultural que contribui para formação dos sujeitos que com ele se relaciona, interferindo na sua maneira de ver, sentir, relacionar com o mundo a sua volta. Com base nesse pressuposto, a questão da produção de LD para o ensino de LE sempre esteve relacionado às tradições, questões culturais de uma determinada época e a "preceitos teóricos"( ALMEIDA FILHO, 2013 p. 17) impostos numa determinada época.

Isso significa que o LD amplia sua relevância enquanto instrumento de ensino porque também é portador de aspectos políticos e culturais, na medida em que reproduz e concebe valores da sociedade no que tange à sua visão da história, da ciência, da explicação dos fatos e ainda do processo de transmissão de conhecimento e na configuração da escola contemporânea.

Apesar de se tratar de um objeto bastante familiar, de fácil identificação, é praticamente impossível defini-lo, conforme assevera Bittencourt (2010):

Por ser um objeto de "múltiplas facetas", o livro didático é pesquisado enquanto produto cultural; como mercadoria ligada ao mundo editorial e dentro da lógica de mercado capitalista; como suporte de conhecimentos e de 
métodos de ensino das diversas disciplinas e matérias escolares; e, ainda, como veículo de valores, ideológicos ou culturais. (Bittencourt, 2010 p.65).

É nessa perspectiva que propusemos analisar textos extraídos os LD: Inglês para o Ensino Médio e It's English, ambos do Ensino Médio. A intenção é discutir como os dois manuais de ensino se diferem quando abordam questões acerca da importância do aprendizado de língua inglesa nos dias atuais. "Esses instrumentos certamente exercem importante influência sobre os sujeitos e seu universo, pois veiculam valores e (pre) conceitos que nortearão as suas ações no meio social em que atuam" (PEREIRA, 2003, p.115). Para isso, apresentamos novos olhares e reflexões que se encontram implícitos nos textos selecionados para análise no que se refere ao modelo neoliberal de educação em contraponto ao modelo de educação humanística. Desse modo, entendemos que o LD se constitui em um recurso pedagógico portador, reprodutor e legitimizador de visões culturais, sociais, ideológicas, mercadológicas ou políticas e que o trato como é dado a esses modelos nos livros didáticos influenciará na constituição dos aprendizes enquanto seres sociais e políticos. Sobre isso concordamos com Pereira (2003), quando declara que:

A escola como instituição está inserida em um contexto social mais amplo e só pode ser entendida se considerada como parte integrante desse contexto. Como toda instituição, a escola constitui-se em um microcosmo da sociedade, refletindo valores e normas dessa sociedade, ao mesmo tempo, contribuindo para o estabelecimento desses valores e normas (PEREIRA, 2003 p.120).

Esperamos que as discussões aqui levantadas culminem em novas práticas de uso e ensino, em que o LD de língua inglesa seja como um objeto que auxilie o professor na exposição ou no reforço dos conteúdos ( LIBÂNEO, 2002), bem como na discussão sobre os conceitos que englobem os novos debates políticos tanto no ensino básico, para o qual os supracitados manuais de ensino foram elaborados, quanto nos meios acadêmicos, especialmente em contextos de formação de professores de língua inglesa.

O texto seguinte compõe a primeira unidade do livro Inglês para o Ensino Médio das autoras Mariza Ferrari e Sara Rubin. O objetivo do texto é exortar os estudantes a aprenderem inglês. Para isso, é dada uma série de explicações para que o aluno compreenda o que faz uma língua ser considerada global e, no final, o texto é concluído com a frase: "So, let's learn English". No entanto as explicações dadas pelas autoras trazem em seus discursos a retórica do neoliberalismo, presentes em frases como: The main reason to for a language to become international is power- the political and economic power of the people who speak it.

Nessa explicação observa-se a ligação que há entre a importância de uma língua ( e consequentemente a importância de se aprender essa língua) com questões ligadas ao poder, ao capital. "Poder" nesse contexto revela condições políticas e econômicas das pessoas que as falam, que é esclarecido por meio da utilização do aposto: power- the political and economic power of the people who speak it.

Observa-se nesse trecho um discurso de caráter utilitarista do aprendizado da língua inglesa que se materializa na importância de aprender uma língua que representa poder. 


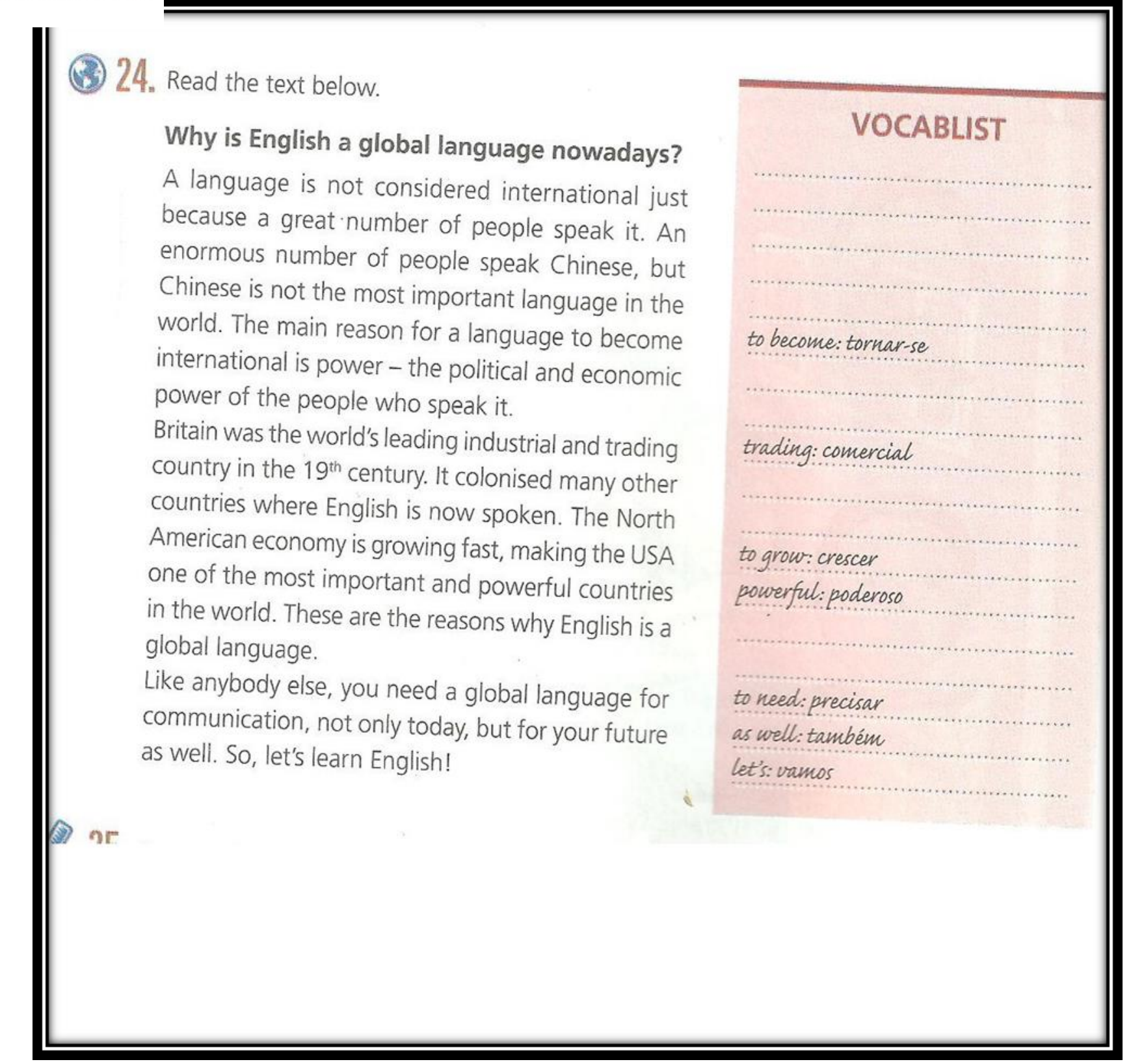

Imagem 1- Texto extraído do livro: Inglês para o Ensino Médio

No parágrafo seguinte as autoras reiteram essa questão quando destacam: " The North American economy is growing fast, making the USA one most important and powerful countries in the world." Nesse trecho a economia, ou seja, o poder, o mercado, o capital é que torna os Estados Unidos a nação mais poderosa do mundo e com isso a língua inglesa se torna também a língua globalizada e mais importante do mundo, razões pelas quais o estudante do ensino médio é exortado a aprender inglês.

Em nenhum momento o aprendizado de língua inglesa é concebido como um conjunto de ações engajadas social, cultural e politicamente, e o indivíduo como atuante e crítico (MENDES, 2002) inserido em contextos sociais, históricos e políticos específicos e nem trata de conhecimentos essenciais que permitam aos estudantes aproximar-se de várias culturas e, consequentemente, propiciar sua integração no mundo globalizado. (PCNEM, 2000). O sentido de globalização e de língua globalizada é traduzido apenas em questões econômicas.

Ao conceber uma aprendizagem significativa é necessário considerar os razões pelas quais é importante aprender uma língua estrangeira. Se considerarmos apenas questões ligadas ao capital e ao lugar que essa língua ocupa no mercado e desprezarmos as competências a serem dominadas talvez seja impossível estabelecermos as razões que de fato 
justificam essa aprendizagem. No contexto de aprendizagem de uma LE é necessário outorgar à importância a questões culturais, conforme sugerem os PCNEM (2000):

A aprendizagem passa a ser vista, então, como fonte de ampliação dos horizontes culturais. Ao conhecer outra(s) cultura(s), outra(s) forma(s) de encarar a realidade, os alunos passam a refletir, também, muito mais sobre a sua própria cultura e ampliam a sua capacidade de analisar o seu entorno social com maior profundidade, tendo melhores condições de estabelecer vínculos, semelhanças e contrastes entre a sua forma de ser, agir, pensar e sentir e a de outros povos, enriquecendo a sua formação (PCNEM, 2000 p.30).

No parágrafo anterior as autoras destacam que o número de falantes de uma língua não a faz uma língua mais importante, nem mais globalizada, tanto que o chinês é a língua mais falada, mas não é mais a mais importante língua do mundo, pois não representa maior poderio político e econômico que Estados Unidos: An enourms number of people speak Chinese, but Chinese is not the most importante language in the world.

O caráter utilitarista da educação é criticado por Marx e Angels quando analisam que a indústria transformou a ciência e educação "em uma força produtiva independente do trabalho, recrutando (o trabalhador) para servir ao capital" (Marx, K., Engels, E, 1985, liv. 1, v.4, cap.12).

O que se espera é que o aprendizado de uma língua estrangeira contribua para a formação total do homem (GRAMSKI,1985), para criação do indivíduo omnilateral que utilize a língua estrangeira para formação integral a para ampliação dos horizontes culturais, para o mundo do trabalho e não apenas para o mercado de trabalho, que contribua para erradicação da visão unilateral da educação que forma o homem apenas para servir ao capital.

O texto apresentado, conforme já exposto, trata-se de um convite ao aluno a aprender inglês, por isso é apresentado na primeira unidade e termina com a frase: " so let's learn English". Mas não é dito ao aluno que o inglês está presentes em práticas sociais da língua materna e que o fato de poder transitar por uma ou mais língua estrangeira permite ao acesso de bens culturais da humanidade ao acesso às tecnologias que fazem parte do seu cotidiano, ampliando as possibilidades de formação para a cidadania.

O segundo texto que apresentamos para análise também compõe a primeira unidade do livro It's English- Ensino Médio e tal como no primeiro texto a intenção do autor é exortar o aluno do Ensino Médio a aprender Inglês. No entanto, são apresentadas cinco situações em que o estudante é instigado a refletir acerca de situações em que a língua inglesa é utilizada de forma integrada á língua portuguesa. São situações relacionadas á jobs, sports, foods, shoppings, musics: práticas sociais de linguagem autênticas e significativas em que a utilização da língua inglesa torna-se natural e indispensável nos contextos em que são apresentadas.

Observa-se aqui um novo domínio discursivo e uma intenção de desenvolvimento de posturas autônomas, críticas e conscientes por parte do aprendiz diante da necessidade do aprendizado de uma língua estrangeira que vai além da instrumentalização linguística, pois a forma como o texto é apresentado intenciona inserir o aprendiz em contextos reais de uso da LE basilado em uma perspectiva enunciativa, volvida para os aspectos comunicativos da linguagem. 


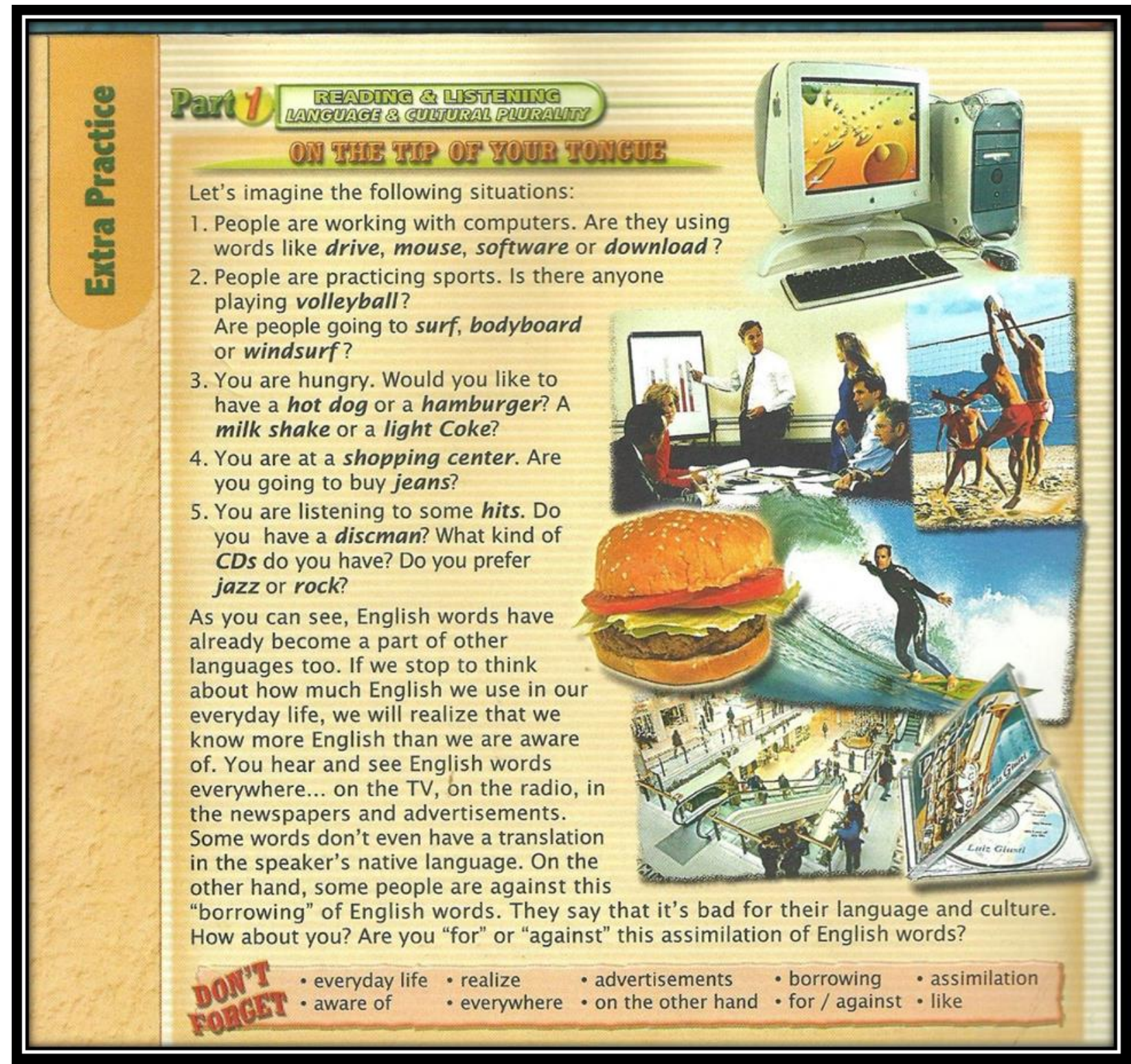

Imagem 2- Texto extraído do livro: It's English

Por meio da utilização da linguagem verbal e não-verbal são apresentadas situações que permitem configurar o ensino-aprendizagem de língua inglesa como uma prática de letramento e, portanto, sócio-historicamente situada. Isso é observado também na estratégia utilizada pelo autor para inserir o aluno em práticas sociais de linguagem em língua estrangeira, o que autoriza--nos compreender uma intenção de proposta de ensino voltado para o desenvolvimento da autonomia e da consciência crítica do aprendiz, condições consideradas basilares para construção de uma educação emancipadora.

Para além do caráter utilitarista que normalmente é atribuído ao aprendizado de uma LE, o texto propõe indagações acerca do papel que a língua inglesa ocupa na vida do aprendiz sugerindo reflexões acerca do quanto vocábulos e expressões em LI estão presentes nas práticas sociais de linguagem na língua portuguesa. Ademais, informa ao aprendiz o quanto ele "já sabe" língua inglesa, colocando-o, dessa forma, em uma posição mais confortável diante do aprendizado de um novo idioma.

Na sequência o autor propõe novos questionamentos acerca do elemento cultural no processo de aprendizagem de uma língua estrangeira no tentame de provocar no aprendiz a importância da consciência cultural. Vale ressaltar que não são apresentadas informações estanques acerca da cultura do país da língua alvo, como normalmente acontece na maioria 
dos manuais de ensino de LE, todavia ao aluno é oportunizado refletir acerca da importância e do papel da cultura nesse processo.

Cleary (2008) advoga que questões culturais sempre ocuparam lugar importante no ensino-aprendizagem de línguas, mas que nos últimos anos, o foco tem mudado para seus aspectos sociais e comportamentais, com ênfase na consciência cultural (cultural awareness), como fator primordial para a comunicação efetiva. A autora defende que a consciência cultural vai além da aprendizagem sobre povos ou culturas, abrangendo, sobretudo a consciência sobre a bagagem cultural do próprio aprendiz e a do outro, bem como o modo como essas influenciam seus comportamentos e formas de como interpretar, negociar e explicar a diversidade cultural para auxiliar na comunicação efetiva com pessoas de outras culturas.

A perspectiva intercultural no ensino-aprendizagem de língua estrangeira é cara, pois intenciona, sobretudo, propiciar o diálogo entre pessoas pertencentes a diferentes culturas, promovendo a integração, e auxiliando os aprendizes na reflexão sobre sua própria cultura, tendo como referência a do outro. Com isso, contribui no desenvolvimento de bases sólidas para o alargamento da convivência intercultural harmoniosa, respeitando os valores que cada um atribui a sua cultura e combatendo as formas de discriminação e etnocentrismo.

A abordagem adotada pelo autor no texto supracitado mostra indícios de uma proposta de ensino-aprendizagem que contribui para erradicação da visão unilateral da educação que forma o homem apenas para servir ao capital, pois privilegia a construção do conhecimento numa perspectiva crítico-reflexiva, visando instrumentalizar o aluno a pensar a crítica e a utilizar o conhecimento adquirido para construção da cidadania. Nesse sentido, o emprego dessa abordagem autoriza-nos a dizer que pode contribuir para formação do homem omnilateral, que ao transitar por uma língua estrangeira amplia seus horizontes culturais e adquire competências necessárias para atuar no mundo do trabalho e não apenas no mercado de trabalho.

\section{Considerações finais}

Com tais considerações, findamos a análise das abordagens dos textos extraídos dos manuais de ensino: Inglês para o Ensino Médio e It's English, cujo objetivo foi discutir as orientações utilitaristas da educação, pautadas na retórica neoliberal em contraponto com o modelo de educação humanista e omnilateral implícitas nos textos selecionados para apreciação. O processo de análise dos textos forneceu pistas para identificar e promover reflexões acerca de concepções ideológicas implícitas nas abordagens utilizadas pelos autores no que tange ao modelo de educação a que se filiam usuários dos manuais e seus respectivos autores.

Busca-se, com isso, subsidiar educadores que atuam em contextos formais de ensino de língua inglesa na compreensão desses modelos para que assim possam estabelecer diálogos interdisciplinares que colaborem para o entendimento dessas representações e, com isso, possam fazer escolhas de livros didáticos com autonomia, criticidade e discernimento, aliando as abordagem adotadas pelos LD com o projeto de educação de cultura e de sociedade que se deseja empreender. Isso se torna relevante porque no processo de ensino-aprendizagem de LI , o LD se constitui no recurso mais importante, quando não o único material de que dispõe a escola, assumindo, assim, o papel de nortear os conteúdos fundamentais do ensino de língua inglesa e de condicionar as abordagens de ensino, na medida em que determina o que e como se deve ensinar.

Desse modo, o livro didático de LI possui um papel relevante na formação da cidadania e determinante no desenvolvimento conhecimento sociohistórico e intercultural dos alunos do ensino médio pois, juntamente com outros recursos e com as metodologias 
adotadas pelos professores contribui para torná-los cidadãos capazes de desenvolver conceitos frente aos valores ideológicos estabelecidos.

Tal constatação compele-nos, mais uma vez, a chamar a atenção para a formação básica dos professores de língua inglesa que, entre outras atribuições, precisa prepará-los para atuar como um analista da linguagem, capaz de apreender os diversos modos pelos quais os sujeitos produzem significados, representam o mundo que o cerca e interage por meio da linguagem, fazendo, assim, uso crítico, autônomo, consciente e independente das obras didáticas que estão a seu alcance. 


\section{Referências}

BRASIL. Secretaria de Educação Fundamental. Parâmetros curriculares nacionais Ensino Médio: linguagens, códigos e suas tecnologias. Brasília: MEC/SEF, 2000.

ALMEIDA FILHO. J.C.P. Codificar conteúdos, processo e reflexão formadora no material didático para ensino-aprendizagem de línguas. In. PEREIRA, A.L. e GOTTHEIM, L. Materiais didáticos para o ensino de língua estrangeira. Processos de criação e contextos de uso. São Paulo: Mercado das Letras, 2013.

AZEVEDO, Janete. M. Lins de. A Educação como Política Pública. Campinas, SP: Autores Associados, 1997.

BIANCHETTI. Roberto G. Modelo Neoliberal e Políticas Educacionais. São Paulo: Cortez, 1996.

BITTENCOURT. Circe Maria Fernandes. Em Foco: História, produção e memória do livro didático. Disponível em http://www.scielo.br/pdf/ep/v30n3/a07v30n3.pdf. Acesso em $\underline{03 / 01 / 16}$

BRZEZINSKI, Iria. Formação de Profissionais da Educação e mudanças na LDB/1996: dilemas e desafios? Contradições e compromissos? In: BRZEZINSKI, Iria. LDB/1996 contemporânea: contradições, tensões e compromissos. São Paulo: Cortez, 2014, p. 112-143.

CAPRIOGLIO, C. A. et al: Análise da L.D.B. da Educação Nacional Lei nº 9394/96, Visão Filosófico-política dos pontos principais. Revista Eletrônica, Metavnoia, São João Del Rei, n. 2, jul. 2000. Disponível em: Acesso em: 24 de dezembro de 2015.

CLEARY, M. Culture in ELT. New Routes, São Paulo, n.36, p. 32-33, set. 2008.

FRIGOTTO, Galdêncio. A produtividade da escola improdutiva. São Paulo: Cortez, 1986. In. BIANCHETTI. Roberto G. Modelo Neoliberal e Políticas Educacionais. São Paulo: Cortez,1996

GALVÃO, A. M. A crise da ética: o neoliberalismo como causa da exclusão social. 4. ed. Petrópolis: Vozes, 1997.

GRAMSCI, Antônio. Os intelectuais e a organização da cultura. Rio de Janeiro: Editora Civilização Brasileira S.A., 1985.

HIRSCHMAN, Albert O. A retórica da intransigência. São Paulo, Companhia das Letras, 1992.

KULLMAN, John. Challenging constructions of the world and the individual in the English Language textbook. In. PEREIRA, A.L. e GOTTHEIM, L (org.) Materiais didáticos para o ensino de língua estrangeira. Processos de criação e contextos de uso. São Paulo: Mercado das Letras, 2013.

LIBÂNEO J. Didática: velhos e novos tempos. Edição do Autor, maio de 2002.

MANACORDA, Mario de Alighiero. Marx e a Pedagogia Moderna. Trad. Nilton Ramos de Oliveira. São Paulo: Cortêz, 1991

MARRACH, S. A. Neoliberalismo e Educação. In: GUIRALDELLI JUNIOR, P. (Org.). Infância, Educação e Neoliberalismo. São Paulo: Cortez, 1996. p. 42-56. MARX, K., ENGELS, F. O capital. São Paulo: Difel, 1985.

MENDES, E. Aprender a língua, aprendendo a cultura: uma proposta para o ensino e Português Língua estrangeira (PLE). In: CUNHA, M.J.C \&SANTOS, P. (org). Tópicos em Português língua estrangeira. 1 ed. Brasília: Editora UnB, pp. 185-199,2002. 
OLIVEIRA. A. M. Introdução Crítica á Literatura sobre Políticas Públicas. Estudos n. 3. Rio de Janeiro. IUPERJ, 1982.

PEREIRA, A. L. Representações de gêneros em livros didáticos de língua estrangeira: reflexos em discursos de sala de aula e relação com discursos gendrados que circulam na sociedade. In. PEREIRA, A.L. e GOTTHEIM, L (org.) Materiais didáticos para o ensino de língua estrangeira. Processos de criação e contextos de uso. São Paulo: Mercado das Letras, 2013. 